\title{
Safety and Efficacy of Low-Dose Oral Immunotherapy for Hen's Egg Allergy in Children
}

\author{
Noriyuki Yanagida ${ }^{a}$ Sakura Sato $^{\mathrm{b}}$ Tomoyuki Asaumi $^{\mathrm{a}}$ Kenichi Nagakura ${ }^{\mathrm{a}}$ \\ Kiyotake Ogura ${ }^{a}$ Motohiro Ebisawa ${ }^{b}$ \\ a Department of Pediatrics and ${ }^{b}$ Clinical Research Center for Allergy and Rheumatology, \\ Sagamihara National Hospital, Kanagawa, Japan
}

\section{Keywords}

Egg $\cdot$ Immunotherapy $\cdot$ Desensitization $\cdot \lg \mathrm{E} \cdot$ Tolerance . Children · Anaphylaxis

\begin{abstract}
Background: The minimal dose for oral immunotherapy (OIT) tolerance is unknown. We investigated the efficacy and safety of low-dose OIT with $1 / 32$ of the volume of a whole egg. Methods: Thirty-three children (aged $\geq 5$ years) with egg allergies confirmed by oral food challenge against $1 / 32$ of a heated whole egg (194 $\mathrm{mg}$ of egg protein) were enrolled. The OIT group ingested a scrambled egg once a day. The volume was gradually increased up to a maximum of $1 / 32$ of a heated whole egg. Egg consumption was completely absent in the control group. Results: There were no significant differences in background between the OIT and control groups. Respectively, $71 \%(15 / 21)$ and $0 \%(0 / 12)$ of the patients in the OIT and control groups exhibited sustained unresponsiveness to $1 / 32$ of a whole egg 2 weeks after stopping OIT after 12 months $(p<0.001) ; 33 \%(7 / 21)$ and $0 \%(0 / 12 ; p=0.032)$, respectively, showed sustained unresponsiveness to $1 / 2$ of a whole egg. Egg white- or ovomucoid-specific lgE levels in the OIT group were significantly lower than at baseline after 12 months. Egg white- or ovo-
\end{abstract}

\begin{tabular}{ll}
\hline KARGER & $\begin{array}{l}\text { ( } 2017 \text { The Author(s) } \\
\text { Published by S. Karger AG, Basel }\end{array}$ \\
E-Mail karger@karger.com & $\begin{array}{l}\text { Karger } \\
\text { www.karger.com/iaa }\end{array}$ \\
& $\begin{array}{l}\text { This article is licensed under the Creative Commons Attribution- } \\
\text { NonCommercial-NoDerivatives 4.0 International License (CC BY- } \\
\text { NC-ND) (http://www.karger.com/Services/OpenAccessLicense). } \\
\text { Usage and distribution for commercial purposes as well as any dis- } \\
\text { tribution of modified material requires written permission. }\end{array}$
\end{tabular}

mucoid-specific IgG as well as IgG4 levels in the OIT group were significantly higher than baseline levels after 1, 3, 6, and 12 months. Adverse allergic reactions were rare, and most symptoms were mild. Conclusions: Low-dose OIT induced sustained unresponsiveness to $1 / 32$ and $1 / 2$ of a whole egg, with no severe symptoms. To improve food allergies, continuous intake of small amounts of these foods may be as effective as the consumption of larger quantities.

(C) 2017 The Author(s)

Published by S. Karger AG, Basel

\section{Introduction}

Hen's egg allergy is one of most common food allergies in children $[1,2]$. Children with a history of anaphylactic reactions to eggs or high egg white-specific IgE levels are reported to be at high risk of severe and persistent egg allergy [3].

A high efficacy of desensitization in response to oral immunotherapy (OIT) has been reported [4]; however, unresponsiveness and tolerance are not easily achieved, and moderate to severe symptoms sometimes occur [46]. Therefore, long-term treatment methods with a higher level of safety are desired [6]. Currently, the most commonly used target dose for OIT against hen's egg allergy 


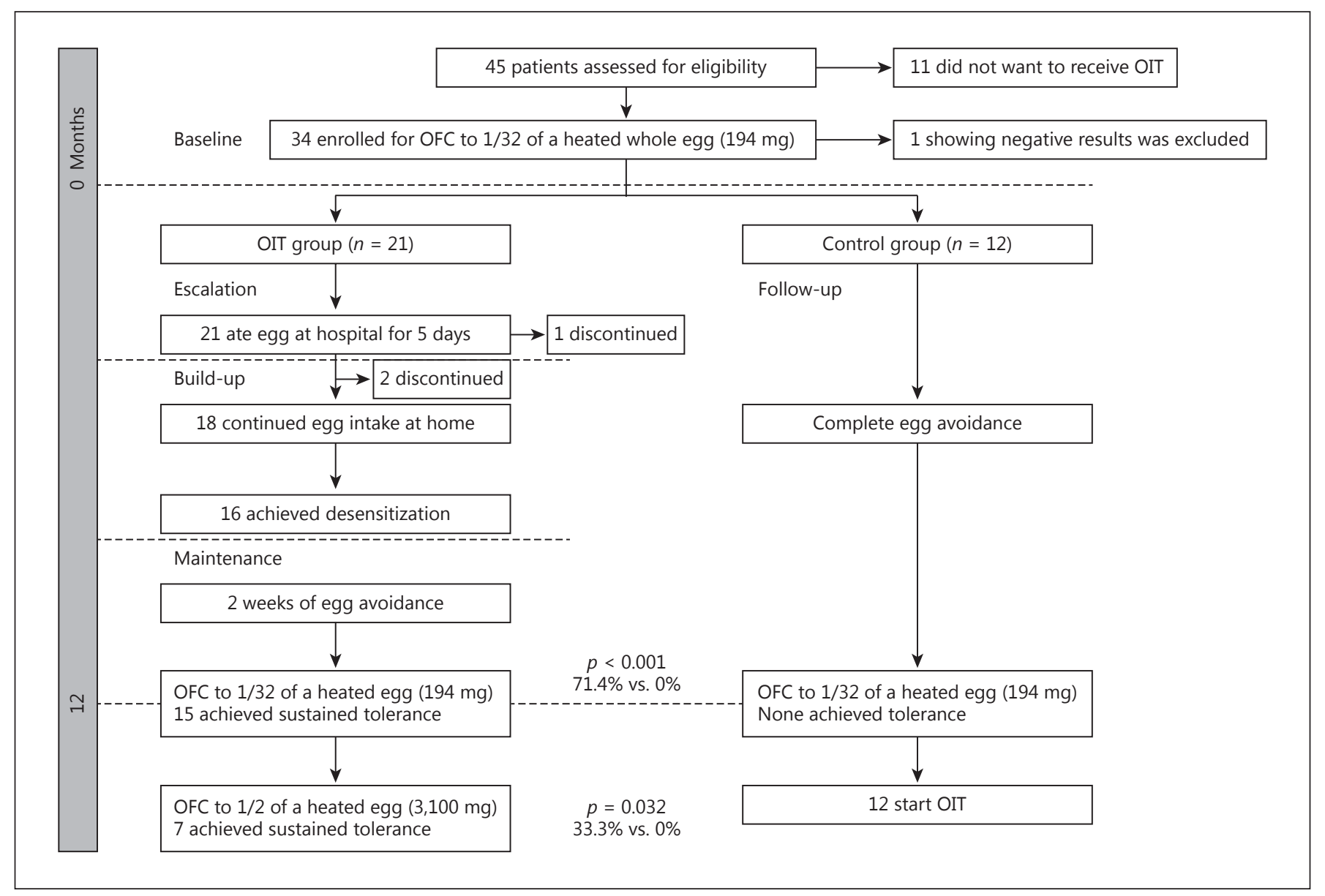

Fig. 1. Study participants. Patients aged $\geq 5$ years who exhibited clearly positive symptoms following an OFC against 1/32 of a whole egg were divided into the OIT and control groups. The guardians of these patients received an explanation of OIT. Three subjects in the OIT group dropped out of the study. One subject, who did not exhibit symptoms, dropped out immediately after the start of OIT because of an inability to follow the protocol. The other 2 subjects withdrew from the study because of frequent mild oral discomfort or mild abdominal pain at home. No subjects dropped out from the control group. The percentage of subjects exhibiting desensitization to $1 / 32$ of a whole egg was $76.2 \%(16 / 21)$

is 1 whole egg $[4,5,7]$. Although Bravin and Luyt [8] reported their experience using baked egg as an oral tolerance food with a target dose of $6,250 \mathrm{mg}$ of egg protein, few studies on low-target volume immunotherapy for egg allergy have been reported [9]. In our previous study on milk OIT, we demonstrated that low-dose OIT using 3 $\mathrm{mL}$ of milk elicited sustained unresponsiveness to a much larger dose of $25 \mathrm{~mL}$ of milk [10]. We hypothesized that low-target volume immunotherapy may be similarly effective against egg allergy. in the OIT group and $0 \%(0 / 12)$ in the control group $(p<0.001)$. The percentage of subjects showing sustained unresponsiveness to $1 / 32$ of a whole egg after 12 months was $71.4 \%(15 / 21)$ in the OIT group and $0 \%(0 / 12)$ in the control group $(p<0.001)$. Of the 15 subjects showing sustained unresponsiveness in the OIT group, 7 were able to consume as much as $1 / 2$ of a whole egg without any symptoms; however, symptoms were induced in 8 subjects. Therefore, the proportions of subjects exhibiting sustained unresponsiveness to $1 / 2$ of a whole egg were $33.3 \%(7 / 21)$ and $0 \%(0 / 12)$ in the OIT and control groups, respectively $(p=0.032)$.

\section{Materials and Methods}

This was a single-center study performed at the Sagamihara National Hospital between January 2013 and September 2015 after approval by the institutional review board of the Sagamihara $\mathrm{Na}$ tional Hospital (UMIN000011202). Candidates (aged $\geq 5$ years) who met the eligibility criteria, with past histories of an anaphylactic reaction or high egg white-specific IgE $>30 \mathrm{kU} / \mathrm{L}$, were divided into two groups, the OIT or the control group after receiving an explanation of OIT and oral food challenge (OFC; Fig. 1; online suppl. Fig. S1; Table S1, S2; for all online suppl. material, see www. karger.com/doi/10.1159/000454807). 
The OIT group was admitted to the hospital for 5 days for build-up (online suppl. Table S3). At home, the OIT group was encouraged to consume 62-194 mg of egg protein in scrambled form once a day. Approximately 12 months later, the daily intake of egg was ceased for 2 weeks, and an open OFC was performed with 1/32 of a whole egg (194 mg). The amount of egg that the patients ate, the severity of provoked symptoms, and treatments administered for the provoked symptoms were recorded in a diary. Patients were instructed to use any medicine when symptoms of grade 2 were provoked (as shown in online suppl. Table S2), and to use an adrenaline self-injector when symptoms of grade 3 were provoked.

\section{Results}

\section{Subject Background}

Initially, 45 candidates met the eligibility criteria, but 11 did not wish to receive OIT and withdrew from the study. A total of 34 subjects in both groups received OFCs with $1 / 32$ of a whole egg; 1 negative case was excluded. Therefore, 33 cases were analyzed (Fig. 1), 21 in the OIT group and 12 in the control group (online suppl. Table S4).

Both groups underwent an open OFC approximately 12 months after the first OFC. In the OIT and control groups, respectively, 18/21 (85.7\%) and 9/12 (75.0\%) of the subjects had a previous history of anaphylaxis; however, there were no significant differences between the groups in terms of the background of the subjects.

\section{Sustained Unresponsiveness to $1 / 32$ and $1 / 2$ of a Whole Egg}

The fraction of subjects showing sustained unresponsiveness to $1 / 32$ of a whole egg 2 weeks after stopping OIT after 12 months was $71.4 \%(15 / 21)$ in the OIT group and $0 \%(0 / 12)$ in the control group $(p<0.001$; Fig. 1$)$. The proportions of subjects exhibiting sustained unresponsiveness to $1 / 2$ of a whole egg were $33.3 \%(7 / 21)$ and $0 \%$ $(0 / 12)$ in the OIT and control groups, respectively $(p=$ $0.032)$.

\section{Immunological Parameters}

Egg white- and ovomucoid-specific IgE levels in the OIT group were significantly lower after 12 months than at baseline. Egg white- and ovomucoid-specific IgG and IgG4 levels in the OIT group were significantly higher after $1,3,6$, and 12 months than the baseline levels (online suppl. Fig. S2).

In the control group, there was no difference between egg white- and ovomucoid-specific IgE, IgG, and IgG4 levels at baseline and those after 12 months (online suppl.
Fig. S3). In the OIT group, no significant differences were observed between responders and nonresponders in terms of the patients' background or parameters tested (online suppl. Table S5).

\section{Symptoms and Treatment}

The OIT group consumed egg a total of 97 times when admitted to the hospital and 5,131 times as outpatients (online suppl. Table S6). The symptom induction rate per intake was $58.8 \%$ in the hospital and $6.5 \%$ at home, of which mild symptoms comprised 45.5 and $5.6 \%$ of hospital and at-home cases, moderate symptoms comprised 13.4 and $0.8 \%$, and severe symptoms comprised 0 and $0 \%$, respectively.

\section{Discussion}

\section{Comparison with Other OITs for Hen's Egg}

In the present study, high-risk subjects with high egg white-specific IgE or a past history of anaphylaxis received low-dose OIT. The symptoms induced in the hospital and at home were minimal compared to those seen conventionally [7], and severe symptoms were not seen. These findings indicate that the present OIT treatment is effective and relatively safe.

\section{Safety of Low-Dose Oral Immunotherapy}

The results suggest that low-dose OIT may be a relatively safe treatment method as the present OIT did not involve increasing the administered dose to more than $1 / 32$ of a whole egg, thereby reducing the risk of occurrence of symptoms associated with such increases [4, 7].

\section{Effect of a Low Target Volume without an}

\section{Increased Dose}

In the present study, a significant difference was observed between the OIT and control groups in terms of sustained unresponsiveness to $1 / 2$ of a whole egg after 12 months, indicating that low levels of intake without increase to a higher dose are effective in inducing tolerance not only to low doses, but also to higher doses.

\section{Immunological Changes}

Despite the low levels of intake, the egg white-specific $\operatorname{IgE}$ and ovomucoid-specific IgE levels were significantly reduced only in the OIT group. Furthermore, IgG4 has been reported to be involved in tolerance induction $[4,5]$. In the present study, the egg white-specific IgG4 levels were found to be significantly higher than the baseline 
levels at all time points, indicating that an immunological change was induced. These findings suggest that even with a low intake a small amount of egg may help to reduce, or even cure, egg allergies.

\section{Conclusion}

This study demonstrates the safety and effectiveness of low-dose OIT in a high-risk population showing severe reactions to very low amounts of egg. Despite the small volume of egg administered, low-dose OIT appeared to induce an immunological change. In addition, the continued intake of small amounts of egg appeared to effectively induce tolerance for larger amounts. Moreover, this treatment may be potentially useful for the reduction of symptoms caused by the accidental consumption of small amounts of egg products. Accordingly, our findings suggest that low-dose OIT should help improve the quality of life of subjects with egg allergies considerably. This study was a nonrandomized open-labeled trial; therefore, future studies involving randomized controlled trials with larger sample sizes are warranted.

\section{Acknowledgement}

We thank the pediatricians, nutritionists, and nurses who participated in patient recruitment and data collection at the Sagamihara National Hospital. This study was supported by a Health and Labor Sciences Research Grant of the Research on Allergic Disease and Immunology from the Ministry of Health, Labor, and Welfare (Motohiro Ebisawa), grant No. 201414009A.

\section{Disclosure Statement}

M.E. received lecture fees from Pfizer. M.E. is in the scientific advisory board of ABV technologies. The rest of the authors have no conflicts of interest to declare.

\section{References}

1 Urisu A, Ebisawa M, Ito K, Aihara Y, Ito S, Mayumi M, Kohno Y, Kondo N: Japanese guideline for food allergy 2014. Allergol Int 2014;63:399-419.

2 Burks AW, Tang M, Sicherer S, Muraro A, Eigenmann PA, Ebisawa M, Fiocchi A, Chiang W, Beyer K, Wood R, Hourihane J, Jones SM, Lack G, Sampson HA: ICON: food allergy. J Allergy Clin Immunol 2012;129:906-920.

3 Hasan SA, Wells RD, Davis CM: Egg hypersensitivity in review. Allergy Asthma Proc 2013;34:26-32.
4 Burks AW, Jones SM, Wood RA, Fleischer DM, Sicherer SH, Lindblad RW, Stablein D, Henning AK, Vickery BP, Liu AH, Scurlock AM, Shreffler WG, Plaut M, Sampson HA; Consortium of Food Allergy Research (CoFAR): Oral immunotherapy for treatment of egg allergy in children. N Engl J Med 2012; 367:233-243.

5 Caminiti L, Pajno GB, Crisafulli G, Chiera F, Collura M, Panasci G, Ruggeri P, Guglielmo F, Passalacqua G: Oral immunotherapy for egg allergy: a double-blind placebo-controlled study, with postdesensitization follow-up. J Allergy Clin Immunol Pract 2015;3:532-539.

6 Vazquez-Ortiz M, Turner PJ: Improving the safety of oral immunotherapy for food allergy. Pediatr Allergy Immunol 2016;27:117-125.
7 Meglio P, Giampietro PG, Carello R, Gabriele I, Avitabile S, Galli E: A new protocol with raw hen's egg. Pediatr Allergy Immunol 2013;24: 75-83.

8 Bravin K, Luyt D: Home-based oral immunotherapy with a baked egg protocol. J Investig Allergol Clin Immunol 2016;26:61-63.

9 Yanagida N, Okada Y, Sato S, Ebisawa M New approach for food allergy management using low-dose oral food challenges and lowdose oral immunotherapies. Allergol Int 2016;65:135-140.

10 Yanagida N, Sato S, Asaumi T, Okada Y, Ogura K, Ebisawa M: A single-center, case-control study of low-dose-induction oral immunotherapy with cow's milk. Int Arch Allergy Immunol 2015;168:131-137. 